\title{
STATISTICAL DESIGN AND DEVELOPMENT OF A LIQUID ORAL FLOATING IN SITU GEL OF METFORMIN HYDROCHLORIDE FOR SUSTAINED RELEASE: PHARMACODYNAMIC AND TOXICITY (HISTOPATHOLOGY) STUDIES
}

\author{
RASHMI MATHEWS ${ }^{*}$, B. PRAKASH RAO ${ }^{2}$, ABBULU KONDE ${ }^{3}$, SUDARSHAN S. ${ }^{1}$, NAWRES A. TAHA ${ }^{4}$, SURESH C. ${ }^{1}$ \\ ${ }^{*}$ Department of Pharmaceutics, ${ }^{2}$ Department of Pharmaceutical Technology, ${ }^{4}$ Department of Pharmacology, Karnataka College of \\ Pharmacy, \#33/2, Thirumenahalli, Hegde Nagar Main Road, Jakkur PO, Bangalore, India 560064, ${ }^{3}$ CMR College of Pharmacy, Affiliated to \\ JNTUH, Hyderabad, India 501512 \\ Email: rashmimathews@gmail.com
}

Received: 15 Nov 2018, Revised and Accepted: 04 Jul 2019

\begin{abstract}
Objective: To statistically design, optimize and evaluate a liquid oral, floating in situ gel of metformin hydrochloride (MH) to increase the gastric residence time (the absorption window being the upper part of the duodenum), sustain and modulate the release behavior of the drug. No liquid
\end{abstract} oral SR formulations of MH are yet available in the market.

Methods: A simple mixing based ionic cross-linking method was used for the formulation. A Two-square Factorial Design was employed and the effect of sodium alginate and three categorical levels of HPMC (K4M, K100M, E50) on the response variables were studied.

Results: The optimized formulation gelled instantaneously in simulated gastric fluid and showed $>24 \mathrm{~h}$ floating. The drug release in $1 \mathrm{~h}$ was $37.98 \%$, followed by a moderate sustained release for $12 \mathrm{~h}$. Pharmacodynamic studies showed a significant reduction in blood glucose levels in Wistar rats. Short term preclinical safety studies revealed no toxicity to pancreatic tissues. On the contrary, faster regeneration of the $\beta$ cells of the islets of Langerhans was observed with the group treated with the optimized formulation. Stability studies revealed a 2-year shelf life.

Conclusion: An elegant, needle-free, in situ gelling, SR liquid oral of metformin hydrochloride could be developed with drug release modulated as per official specifications for SR formulations of MH. This would be an interesting alternative for geriatric patients who find it difficult to swallow bulky tablets.

Keywords: Liquid oral floating in situ gel, Metformin hydrochloride, Least square fit model, Pharmacodynamic study, Toxicity studies

(C) 2019 The Authors. Published by Innovare Academic Sciences Pvt Ltd. This is an open-access article under the CC BY license (http://creativecommons.org/licenses/by/4.0/) DOI: http://dx.doi.org/10.22159/ijap.2019v11i5.30793

\section{INTRODUCTION}

The successful design and optimization of effective drug delivery systems have become an integral part in improving various parameters such as the degree and rate at which the administered drug reaches the systemic circulation and research is continuously progressing in this area. Diseases like diabetes need much attention as glucose levels tend to increase after a meal and it should be maintained for the whole day for proper body activity. Metformin hydrochloride is an oral hypoglycemic agent and the first drug of choice to treat patients with Type II diabetes. It has an absolute oral bioavailability of $40 \%$ to $60 \%$. It is highly hydrophilic with gastrointestinal absorption occurring mainly in the upper part of the intestine with peak plasma concentrations $\left(\mathrm{C}_{\max }\right)$ at $4.8 \mathrm{~h}$. It has a short half-life of 1.5 to $4.5 \mathrm{~h}$ and therefore the development of gastro retentive systems of the drug would help sustain the drug release and improving oral bioavailability. When large doses of $\mathrm{MH}$ are needed, the frequency of dosing may be 2 to 3 times a day which may reduce patient compliance and therefore liquid oral sustainedrelease (SR) formulations that give once a day dosing would be preferable.

The tablet and capsule dosage forms have to be swallowed as a whole unit and in case of dosage adjustment, these cannot be broken into halves as they are designed for controlled release and the floating ability also depends on dimensions of the tablet. Elderly and dysphagic patients find it difficult to swallow bulky tablets and capsules. In such cases, high doses of the drug can be incorporated into liquid oral in situ gelling (ISG) formulations [1, 2]. Novel drug delivery systems like in situ gelling systems reduce adverse reactions, toxicity and frequency of dosing with improved efficacy, patient compliance and convenience [3-6]. In situ, gelling occurs due to one or a combination of different stimuli like $\mathrm{pH}$ changes, temperature modulation, solvent exchange and can be achieved in a gastric environment [7-9]. Various natural and synthetic polymers including polysaccharides like carrageenan, gellan gum, pectin and sodium alginate have been used in the development of in situ gelling systems which undergoes a phase transition in presence of various di and trivalent ions [10-12]. Sodium alginate is a natural and hydrophilic polymer suitable for the entrapment of water-soluble drugs [13-15], widely used in pharmaceutical formulations [16-18]. HPMC is used as a viscosity modifier. Sorbitol is used as a sweetener in liquid orals and studies have shown that gels containing 10-17\% sorbitol sustained the release of drug in rat stomach and a bioavailability of approximately $90 \%$ was achieved from orally administered syrups $[19,20]$.

The current research work aimed at the development and evaluation of a floating, liquid oral dosage form of Metformin hydrochloride for sustained release, along with providing evidence regarding modulated drug release as per official specifications. No liquid oral sustained-release formulations of Metformin hydrochloride are available in market up to date and therefore an attempt is being to develop the same.

\section{MATERIALS AND METHODS}

\section{Materials}

Metformin hydrochloride was procured from National Pharmaceuticals, Birgunj. Sodium alginate, pectin, calcium carbonate, HPMC (K4M, K100M, E50), sodium citrate, and sorbitol were obtained from Yarrow Chem Products, Mumbai.

\section{Methods}

Pre-formulation studies

\section{Drug-excipient compatibility studies by FT-IR}

To investigate any possible interaction between the drug and polymers used, the IR spectrum of the pure drug $(\mathrm{MH})$ and the 
binary mixture of drug and polymers was taken using FTIR (UV visible spectrophotometer, Alpha Bruker) [21-24].

\section{Design of experiment and statistical optimization}

The conventional methods of experimentation by changing one variable at a time being time-consuming, the Design of Experiment (DOE) was done using the JMP Statistical Software (Trial version 13). The polymers and other quantities were selected based on reported literature on similar studies and initial screening experiments done to identify the optimum conditions and quantities required. Evaluation of preliminary batches was done based on responses such as in vitro gelling capacity, drug release and pourability (relative viscosity), to select the working concentration range of polymers (factors). The Two-Square Factorial design was used, taking two levels of the independent variable sodium alginate (Factor 1) coded at high and low levels and three categorical levels of HPMC (Factor 2) i.e., E50, K4M, K100M.

\section{Formulation of metformin $\mathrm{HCl}$ oral in situ gel by a simple mixing method}

Polymeric solutions of sodium alginate $(0.7 \%$ and $1.25 \% \mathrm{w} / \mathrm{v})$ with pectin $(0.5 \% \mathrm{w} / \mathrm{v})$ were prepared by adding it to ultrapure water containing sodium citrate $(0.25 \% \mathrm{w} / \mathrm{v})$ and calcium carbonate $(1 \%$ $\mathrm{w} / \mathrm{v}$ ). This solution was then heated to $60^{\circ} \mathrm{C}$ with continuous stirring. After cooling to below $40^{\circ} \mathrm{C}$, HPMC $(0.5 \% \mathrm{w} / \mathrm{v})$ was added, followed by $500 \mathrm{mg}$ of $\mathrm{MH} / 5 \mathrm{ml}$, sorbitol $(10 \% \mathrm{w} / \mathrm{v})$ and sodium benzoate $(0.1 \% \mathrm{w} / \mathrm{v})$. Ultra-pure water was used as a solvent [2527]. A batch minimum of $100 \mathrm{ml}$ was prepared.

\section{Evaluation}

\section{$\mathrm{pH}$ of the gel}

The $\mathrm{pH}$ of the formulation was determined using a calibrated $\mathrm{pH}$ meter and readings taken in triplicate [28-29].

\section{Determination of in vitro gelation time and floating behavior}

In vitro gelation time was determined by placing the sols in an open vial tied to the paddle in the USP Type II Dissolution apparatus (Paddle type) containing $900 \mathrm{ml}$ of SGF $\left(0.1 \mathrm{~mol} \mathrm{~L}^{-1} \mathrm{HCl}, \mathrm{pH} 1.2\right)$ at $37 \pm 0.5^{\circ} \mathrm{C}$. The buoyancy lag time and duration of floating was noted. The readings were taken in triplicate [30-33].

\section{Viscosity}

The viscosity of the sol and gel in $0.1 \mathrm{~N} \mathrm{HCl}$ was determined using Brookfield viscometer (DV-II+Pro LV model). The selected formulations $(250 \mathrm{ml})$ were poured into the sample adaptor of the viscometer and the viscosity measured at room temperature using SC4-18 spindle for the sols and LV2 spindle for the gels. The angular velocity was gradually increased from 10 to $50 \mathrm{rpm}$ with a $6 \mathrm{sec}$ wait period, the hierarchy reversed and the average taken. The viscosity measurements were made in triplicate [34].

\section{In vitro drug release and kinetics}

The drug release study was carried out using USP Type II dissolution apparatus (Paddle type, Electrolab). $5 \mathrm{ml}$ of the formulation was kept in vials and dissolution done. At predetermined time intervals, $5 \mathrm{ml}$ of sample solution was withdrawn, filtered through a $0.45 \mu \mathrm{m}$ membrane filter, suitably diluted and analyzed by UV spectrophotometrically at $232 \mathrm{~nm}$. The same amount of fresh dissolution medium was replaced immediately after withdrawal of the test sample [35-37]. The mechanism of drug release was studied by fitting the dissolution data in the zero-order, first-order, Higuchi model, Korsemeyer-Peppas equation following model-dependent kinetics. Based on the slope and $\mathrm{r}^{2}$ values obtained, the mechanism of drug release was determined [38-41].

\section{Optimization}

The values obtained after evaluating the responses experimentally were fed into the JMP software and the data analyzed. The numerical optimization techniques and the least square fit model was employed. The desirability approach (using Prediction profiler) was used to generate the optimum settings for the formulation.
Optimization was done for the responses by keeping in vitro gelation and drug release at $1 \mathrm{~h}$ at maximum while that at $8 \mathrm{~h}$ and $12 \mathrm{~h}$ were kept in the range [42]. The optimization target and constraints were set based on the official IP specifications.

\section{In vivo pharmacodynamic study}

The animal studies were done according to the protocol approved by the Institutional Animal Ethics Committee formed under the CPSCEA guidelines (CPSEA Registration No: 1564/PO/a/11/CPSEA-23-112012). Wistar rats weighing between $150-250 \mathrm{~g}$ were divided into 3 groups, each with six rats. They were acclimatized for a week prior to the experiment, caged in a fully ventilated room at a temperature of $25 \pm 2^{\circ} \mathrm{C}$, with a $12 \mathrm{~h}$ light/dark cycle with free access to standard chow diet and water. These have fasted for $24 \mathrm{~h}$ and diabetes-induced with Streptozotocin $40 \mathrm{mg} / \mathrm{kg}$ (i. v). Treatment was started once the rat became diabetic. Group-1(control) was treated with physiological saline), Group-2 with the pure drug solution $(0.116 \mathrm{ml})$ of $\mathrm{MH}(58.31$ $\mathrm{mg} / \mathrm{kg}$ dose) and Group- 3 was given the optimized liquid oral ( 0.116 $\mathrm{ml}$ ) of $\mathrm{MH}(58.31 \mathrm{mg} / \mathrm{kg}$ dose). Comparison was done between the groups to identify any significant differences [43-45].

\section{Statistical analysis}

Statistical analysis was carried out using the ANOVA and p-values less than 0.05 were considered statistically significant.

\section{Toxicity (Histopathological) studies}

At the end of the animal study, the rats were fasted overnight, anesthetized with Ketamine $(80 \mathrm{mg} / \mathrm{kg})$ and Xylazine $(8 \mathrm{mg} / \mathrm{k}-\mathrm{g})$ followed by terminal exsanguination. The pancreas was carefully excised, rinsed in ice-cold saline and stored in $10 \%$ formalin for tissue characterization. It was then embedded in paraffin, sectioned at $4 \mu \mathrm{m}$ using a semi-automated microtome and the tissue sections mounted on glass slides using a hot plate. After deparaffinization with xylene, rehydration with $100 \%, 90 \%$ and $70 \%$ dilutions of ethanol, the sections were stained with Hematoxylin and Eosin $(\mathrm{H}$ and E) and the changes in pancreatic tissues observed [46].

\section{Stability studies}

Accelerated stability studies were conducted as per ICH Q1C guidelines on the optimized formulation to assess the stability with respect to physical appearance, drug content and drug release characteristics after storing in a stability chamber (Thermolab) at 40 ${ }^{\circ} \mathrm{C} / 75 \%$ (RH) for 6 mo. The formulation was filled in an HDPE bottle with induction sealed CRC caps $[47,48]$.

\section{RESULTS AND DISCUSSION}

\section{Preformulation study}

\section{Drug-excipient compatibility studies by FT-IR}

No significant shifts or reduction in the intensity of the FTIR bands of MH were seen. Characteristic shoulders were observed at 1623 $\mathrm{cm}^{-1}$ for the $\mathrm{C}=\mathrm{N}$ stretching, $1544 \mathrm{~cm}^{-1}$ for the $\mathrm{N}-\mathrm{H}$ bending, $1164 \mathrm{~cm}^{-}$ 1 for the of the C-N stretch, $3288 \mathrm{~cm}^{-1}$ for the $\mathrm{N}-\mathrm{H}$ stretching respectively. These bands were also observed for the physical mixture of polymers along with $\mathrm{MH}$, thus confirming that there was no interaction between $\mathrm{MH}$, polymers and excipients used and that they were compatible with the drug.

\section{Metformin HCl liquid oral in situ gel}

In the prepared formulation, sodium alginate along with pectin were used as to modulate and prolong the drug release and the combination gave a synergistic effect. HPMC was incorporated as a viscosity enhancer in order to achieve the desired consistency so as to facilitate sustained release and also reduced the amount of sodium alginate used. Calcium carbonate was used as a source of calcium ions, sodium citrate to prevent gelation outside the gastric environment and to complex with the free calcium ions and release them in the highly acidic environment of the stomach. Sorbitol, polyhydroxy alcohol, was used as stabilizing agent cum sweetener (it does not increase the blood glucose levels) and sodium benzoate as preservative. The formulation remained in the liquid form until it reached the stomach where instantaneous gelation occurred, thereby sustaining the drug release. The ion activated gel so 
formed floated on the gastric fluids. The basic mechanism of floating was that the calcium carbonate present in the formulation as an insoluble dispersion becomes soluble in the acidic medium, releasing $\mathrm{Ca}^{2+}$ and $\mathrm{CO}_{2}$ gas, causing gelation of the polymer and the gas released in the entrapped gel matrix caused the system to float [49]. The $\mathrm{pH}$ of the formulations was 6.8-7.2 which was within the acceptable range for liquid orals. The carbonation also had a synergistic effect in the tastemasking (in the $\mathrm{pH}$ range of 4 to 9). The viscosity was near or greater than 1 (the maximum limit a flowing liquid can have).

\section{Design of experiment and ANOVA}

The Two-Square Factorial design was used to discover the vital factors in the formulation that influence the various responses, including physicochemical properties and drug release. The factors used in the formulation, their proportions as per the design and the values of the responses are as enlisted in table 1 and the response variables of prepared formulations F1-F6 are seen in table 2. Each of the readings was performed in triplicate and the average taken.

Table 1: Formulation chart of metformin $\mathrm{HCl}$ in situ gel as per fit model design (JMP)

\begin{tabular}{|c|c|c|c|c|c|c|c|}
\hline \multicolumn{2}{|c|}{ Formulation code } & F1 & F2 & F3 & F4 & F5 & F6 \\
\hline \multicolumn{2}{|c|}{ Metformin Hydrochloride (g) } & 1 & 1 & 1 & 1 & 1 & 1 \\
\hline \multicolumn{2}{|c|}{ Sodium alginate (mg) } & 125 & 70 & 125 & 70 & 125 & 70 \\
\hline \multicolumn{2}{|c|}{ Pectin (mg) } & 50 & 50 & 50 & 50 & 50 & 50 \\
\hline & E50 & 50 & 50 & & & & \\
\hline \multirow[t]{2}{*}{ (mg) } & $\mathrm{K} 4 \mathrm{M}$ & & & & 50 & 50 & \\
\hline & K100M & & & 50 & & & 50 \\
\hline \multicolumn{2}{|c|}{ Ultra-Millipore water (ml) } & 10 & 10 & 10 & 10 & 10 & 10 \\
\hline
\end{tabular}

*All other quantities in the formulation are constant i.e., Sodium citrate 25 mg, Sorbitol 10\%, Calcium carbonate100 mg, Sodium benzoate 10 mg

Table 2: Response variables of the prepared formulations F1-F6

\begin{tabular}{|c|c|c|c|c|c|c|}
\hline Formula code & pH & Gelation time (sec) & Floating lag time (sec) & Viscosity of sol (cP) & Viscosity of gel (cP) & Drug content (\%) \\
\hline F1 & 7.2 & 2 & 75 & 410 & 1500 & 92.35 \\
\hline $\mathrm{F} 2$ & 7.3 & 10 & 110 & 360 & 1200 & 94.26 \\
\hline F3 & 7.1 & 2 & 150 & 1010 & 4240 & 95.65 \\
\hline F4 & 6.9 & 3 & 96 & 380 & 1620 & 98.26 \\
\hline F5 & 6.8 & 2 & 130 & 490 & 1840 & 96.73 \\
\hline F6 & 7.1 & 4 & 195 & 920 & 4110 & 93.78 \\
\hline
\end{tabular}

The line of fit for the three grades of HPMC in the plot of sodium alginate versus $\%$ Cumulative drug release at $3 \mathrm{~h}$ and the correlation
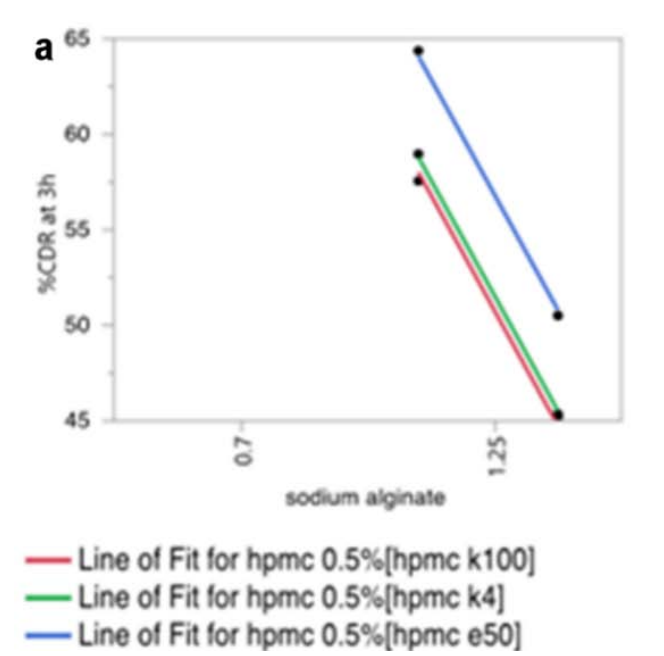

between the actual and predicted values for \%CDR for $3 \mathrm{~h}$ is seen in fig. 1a and $1 \mathrm{~b}$.

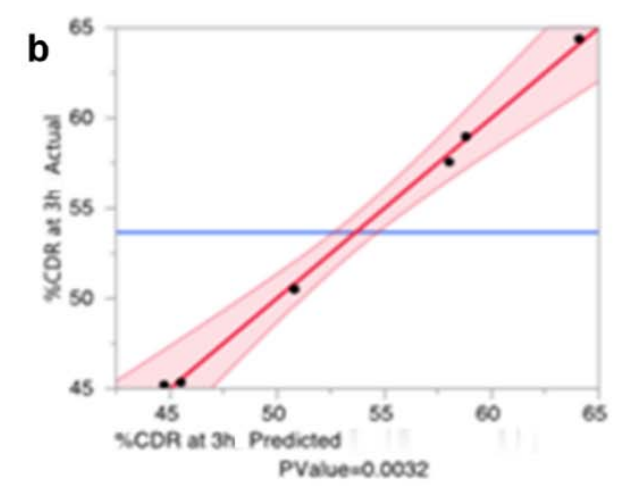

Fig. 1: (a) Line of fit of the different grades of HPMC used for sodium alginate vs \%CDR at $3 \mathrm{~h}$ (b) Predicted vs Actual values

The line of fit showed a linear regression line with confidence intervals fixed at $95 \%$ confidence for the predicted value (fit). The equations from the linear regression analysis for the responses are as follows:

Gelation time, $\mathrm{R} 1=3.833-1.833 \mathrm{X} 1+2.166 \mathrm{X} 2 \mathrm{a}-1.333 \mathrm{X} 2 \mathrm{~b}-$ $0.833 \mathrm{X} 2 \mathrm{c}$ (Eq 1)

Floating lag time, $R 2=126-7.6666 \times 1-33.5 \times 2 a-13 X 2 b+46.52 c$ (Eq 2)

Viscosity of sol, R3 $=595+41.666 \mathrm{X} 1-210 \mathrm{X} 2 \mathrm{a}-160 \mathrm{X} 2 \mathrm{~b}+370 \mathrm{X} 2 \mathrm{c}$ (Eq 3)
Viscosity of gel, $\mathrm{R} 4=2418.333+108.333 \mathrm{X} 1-1068.333 \mathrm{X} 2 \mathrm{a}-$ $688.333 \times 2 b+1756.666$ X2c (Eq 4)

\%CDR at $1 \mathrm{~h}, \mathrm{R} 5=39.258-8.401 \mathrm{X} 1+11.306 \mathrm{X} 2 \mathrm{a}-2.923 \mathrm{X} 2 \mathrm{~b}-$ 8.383X2c (Eq 5)

$\% \mathrm{CDR}$ at $3 \mathrm{~h}, \mathrm{R} 6=53.661-6.641 \mathrm{X} 1+3.783 \mathrm{X} 2 \mathrm{a}-1.501 \mathrm{X} 2 \mathrm{~b}-$ 2.281X2c (Eq 6)

\%CDR at $8 \mathrm{~h}, \mathrm{R} 7=90.34-3.61 \mathrm{X} 1-1.48 \mathrm{X} 2 \mathrm{a}+1.11 \mathrm{X} 2 \mathrm{~b}+0.37 \mathrm{X} 2 \mathrm{c}(\mathrm{Eq}$ 7)

$\%$ CDR at $12 \mathrm{~h}, \mathrm{R} 8=98.66-0.826 \mathrm{X} 1-0.915 \mathrm{X} 2 \mathrm{a}+0.61 \mathrm{X} 2 \mathrm{~b}(\mathrm{Eq} 8)$ 
Where X1 was the sodium alginate concentration and X2a indicated HPMC E50 (coded level-1), X2b represented HPMC K4M (coded level 0) and X2c represented HPMC K100M (coded level+1) respectively. The 3D surface response curve (fig. 2) also showed the relationship between the polymer concentrations and drug release at $3 \mathrm{~h}$. The regression analysis is a statistical tool used to determine the probable change in one variable for a given change in another. The magnitude of the change in response caused by varying the factor level is denoted as an effect. The main effect is the effect of a factor averaged over all the levels of other factors. Such data is suitably modelled to generate mathematical relationships between the independent and dependent variables. The response surface is a graphical depiction of the mathematical relationship [50].

\section{Rheological studies}

The formulations were sols at lower $\mathrm{pH}$ (indicating ease of pourability and swallowing) while they gelled at gastric $\mathrm{pH}$, thus improving the gastric residence time and sustaining the release. The viscosity of the sols varied from 360 to $1010 \mathrm{cps}$ while that of the gel varied from 1200 to $4240 \mathrm{cps}$ on changing the rpm from 10 to 50 (at $37^{\circ} \mathrm{C}$ ). The hydrogels exhibited pseudoplastic rheology, the value of the flow index (n) being less than 1. Smaller the flow index values, more marked is the shear thinning. By knowing rheological properties, the composition can be modulated, designing hydrogels with optimal drug release characteristics and adequate consistency [51].

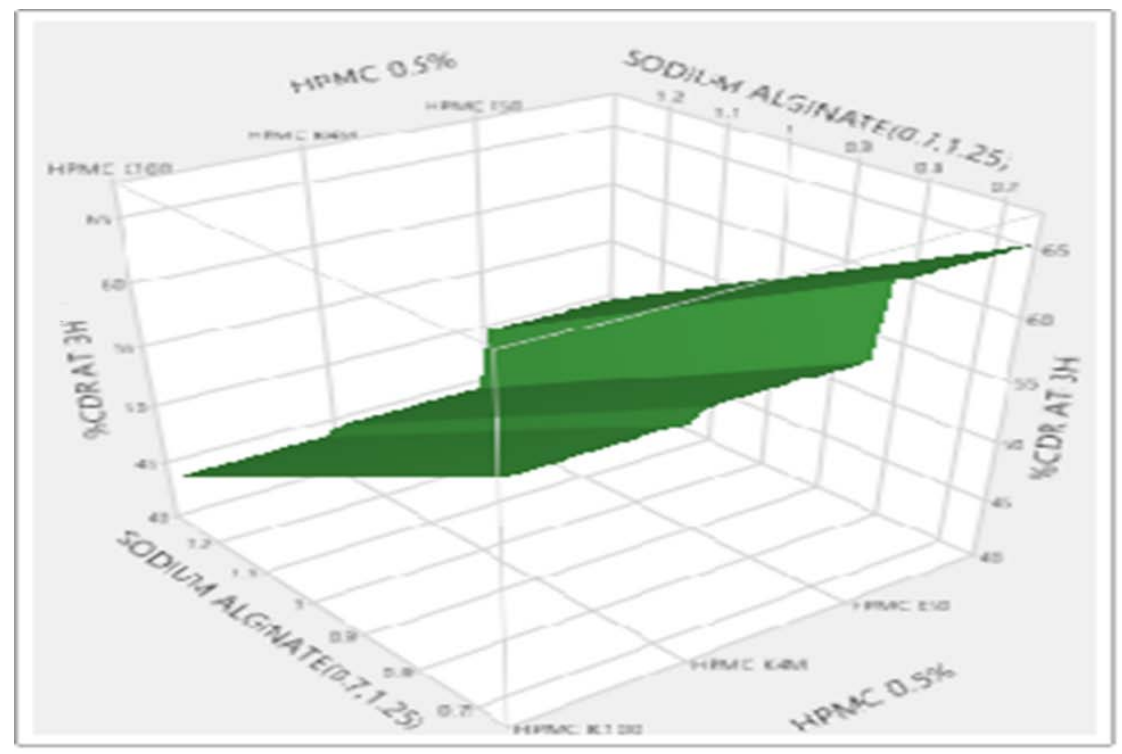

Fig. 2: 3-D surface response graph for $3 \mathrm{~h}$ drug release

For the above-mentioned responses, the probability value was found to be significant (i.e., ${ }^{*} \mathrm{p}<0.05$ ) for viscosity of the sol and gel as well as drug release at $12 \mathrm{~h}$ (table 3 ).
Thus, the ANOVA established the statistical significance of the two factors in formulating a liquid oral sustained release formulation of $\mathrm{MH}$.

Table 3: Summary of ANOVA for significant responses as per least square fit model

\begin{tabular}{lllll}
\hline Source & Sum of squares & DF & F ratio & p-value Prob>F \\
\hline Viscosity of sol & & & & \\
Model & 423616.67 & 3 & 302.5833 & $0.0420^{*}$ \\
Sodium alginate & 10416.67 & 1 & 22.3214 & $0.0023^{*}$ \\
HPMC & 413200.00 & 2 & 442.7143 & $0.003^{*}$ \\
Corr Total & 424550.00 & 5 & - & \\
Viscosity of gel & & & & $0.0011^{*}$ \\
Model & 9472450.0 & 3 & 3157483 & $0.0477^{*}$ \\
Sodium alginate & 70416.7 & 1 & 19.4700 & $0.0008^{*}$ \\
HPMC & 9402033.3 & 2 & 1299.820 & - \\
Corr Total & 9479683.3 & 5 & - & $0.0383^{*}$ \\
\%CDR at 12h & & & & $0.0209^{*}$ \\
Model & 6.7049667 & 3 & 25.3065 & 0.0635 \\
Sodium alginate & 2.6047000 & 1 & 46.4269 & - \\
HPMC & 2.6047000 & 2 & 14.7464 & \\
Corr Total & 6.8816000 & 5 & - & \\
\hline
\end{tabular}

$\left({ }^{*}\right.$ p value significant i.e., $\left.<0.05\right)$

Table 4: Effective summary as per least-square fit model (JMP)

\begin{tabular}{lll}
\hline Source & Log worth & Value \\
\hline Sodium alginate $(0.7,1.25)$ & 2.908 & 0.00124 (significant) \\
HPMC $0.5 \%$ & 2.647 & 0.00225 (significant) \\
\hline
\end{tabular}

The logworth values as seen in table 4 are also a good statistic for plotting and assessing significance. A log worth value exceeding 2 indicates that the effects are significant at 0.01 level. 
In vitro gelation, floating and drug release studies

The nature of floating was as seen in fig. 3. The formulation instantaneously gelled and floated for more than $24 \mathrm{~h}$, on contact with SGF.

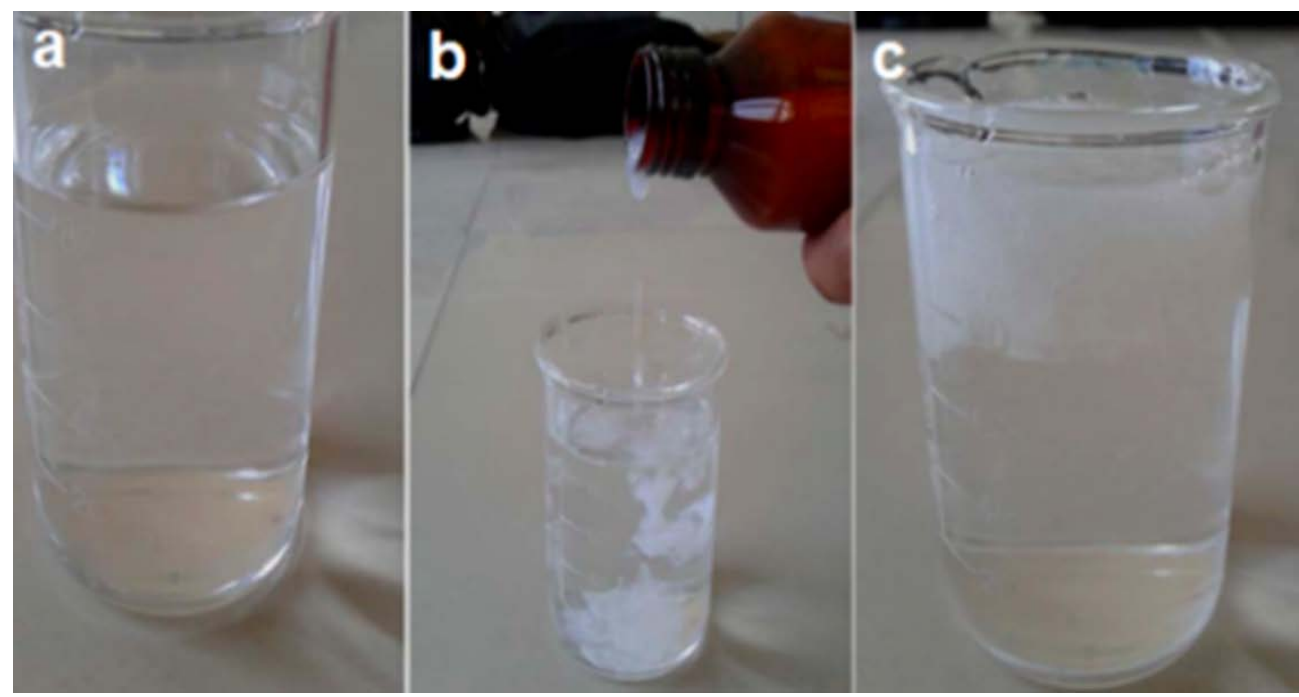

Fig. 3: (a) Liquid oral (b) Ionic gelation of the liquid oral on contact with SGF, (c) Floating in situ gel

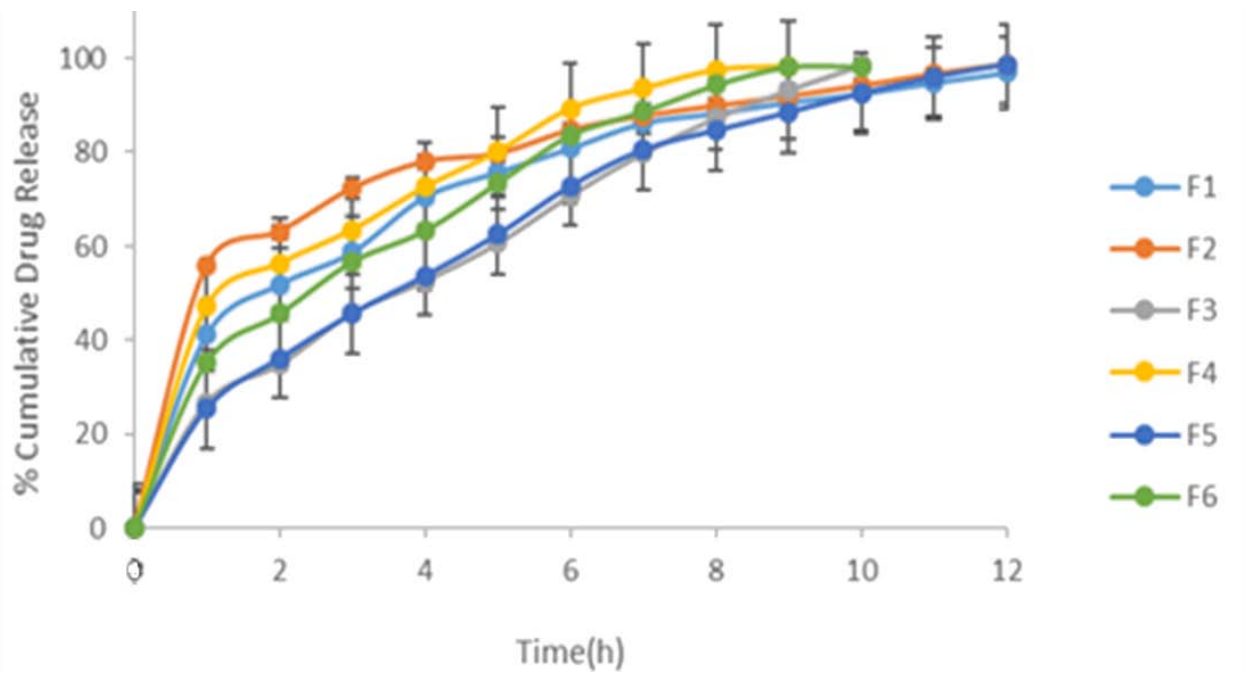

Fig. 4: In vitro dissolution profiles of the drug from the prepared formulations F1-F6 *Each reading was determined in triplicate (n=3), average taken, data given as mean \pm SEM)

The in vitro drug release studies for the formulations were done and the results compared (fig. 4). The formulation F5 showed maximum sustained drug release. The drug release data fitted into the various models showed very close $r^{2}$ values (above 0.8 ). The $r^{2}$ values of the Higuchi model of all the formulations showed higher values indicating that the drug release was directly proportional to square root of time. But $\mathrm{n}$ values ranging from 0.2033 to 0.5239 indicated Fickian diffusion mechanism. It may be coincident. However, $n$ values of Korsmeyer-Peppas strongly indicated Fickian diffusion mechanism.

\section{Statistical optimization}

For each of the responses (Yi), the desirability function D (Yi) assigned values ranging from a completely undesirable value of 0 to a completely desirable response of 1 . The optimized formulation was prepared according to Prediction profiler (fig. 5) and evaluation is done. Profiling is an approach to visualize response surfaces (crosssectional view) by seeing what could happen if one or two factors are changed at a time. Interactive profilers help in exploring opportunity spaces. There was a good relationship between the experimented and predicted values, which confirmed the practicability and validity of the model.

The in vitro drug release of the optimized formulation and marketed product were compared (table 5) and the similarity factor was found to be 75.404 . The marketed product released the drug at the minimum limit (25\%) while the optimized product released the drug towards the average value of the official limit (37.98\%) and has been graphically represented as seen in fig. 6 . 


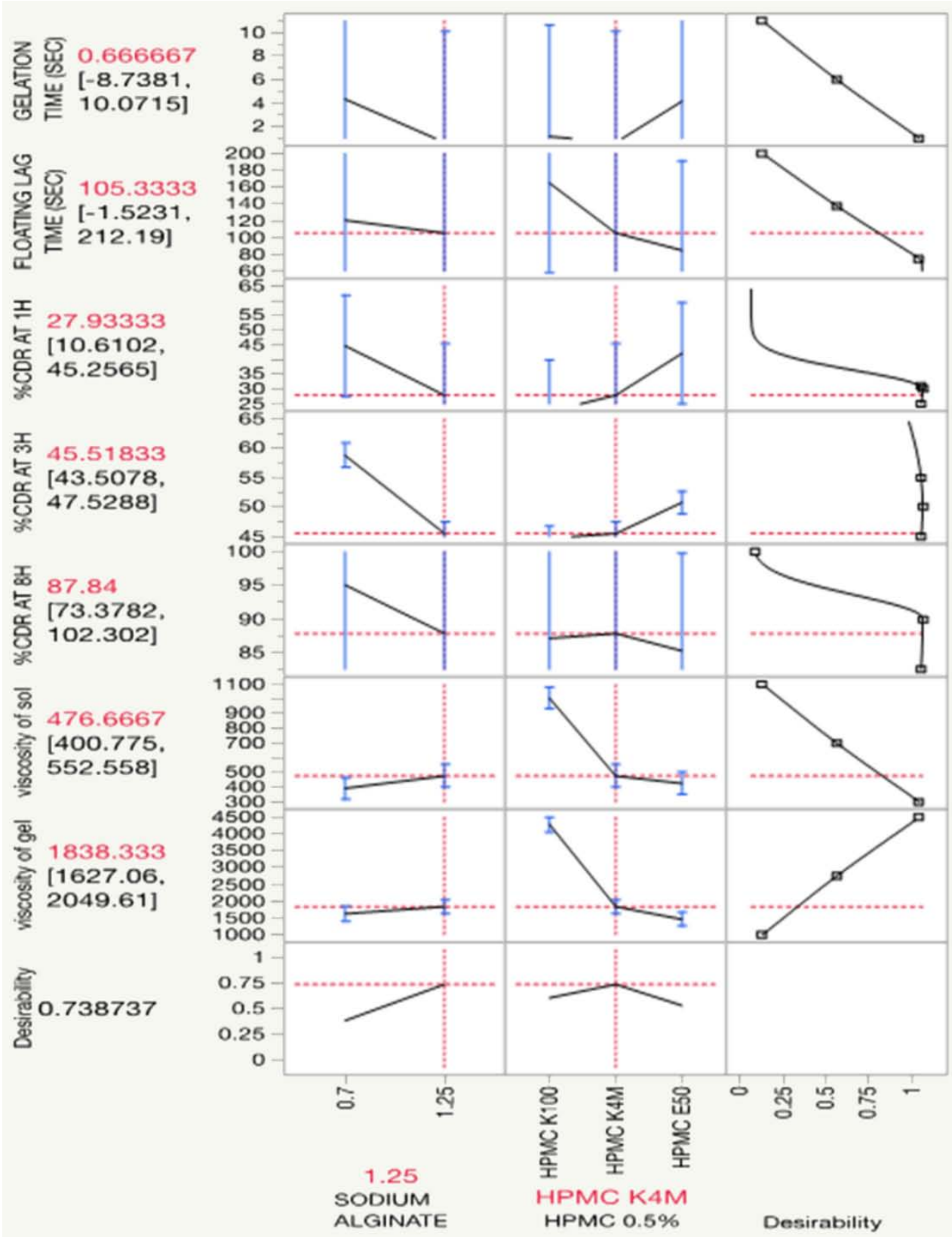

Fig. 5: Statistical optimization done using prediction profiler

Table 5: Drug release profile of optimized formula and comparison with marketed SR product of metformin hydrochloride

\begin{tabular}{|c|c|c|c|}
\hline Time (h) & \%CDR (Optimized formula) & \%CDR (Marketed product) & IP specifications \\
\hline 1 & 37.986 & 25.593 & Not less than $25 \%$ and not more than $50 \%$ in $1 \mathrm{~h}$ \\
\hline 2 & 48.076 & 31.746 & \\
\hline 3 & 61.669 & 45.12 & Not less than $45 \%$ and not more than $75 \%$ in $3 \mathrm{~h}$ \\
\hline 4 & 69.463 & 53.090 & Not less than $80 \%$ in $8 \mathrm{~h}$ \\
\hline 5 & 73.496 & 62.526 & \\
\hline 6 & 75.983 & 72.506 & \\
\hline 7 & 79.173 & 80.780 & \\
\hline 8 & 83.280 & 84.27 & \\
\hline 10 & 87.243 & 89.293 & \\
\hline 12 & 93.263 & 93.429 & \\
\hline
\end{tabular}




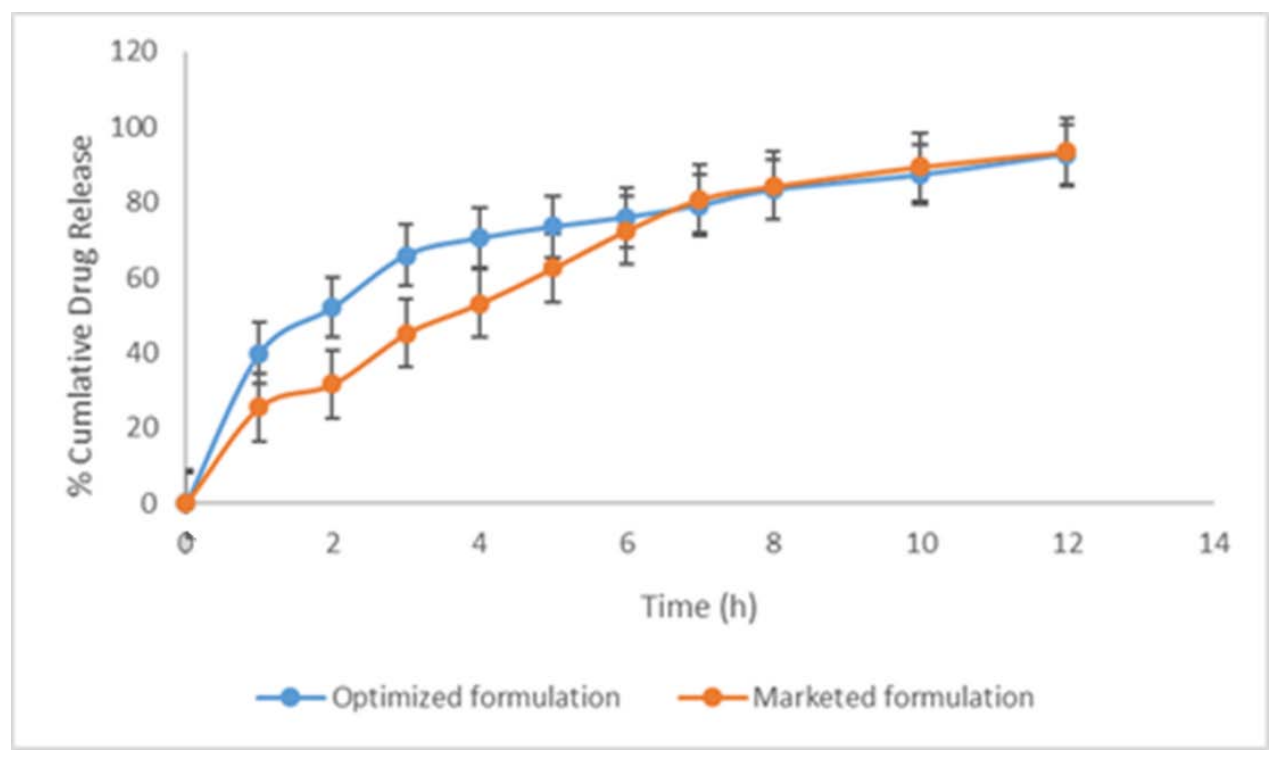

Fig. 6: Comparison of dissolution profiles for marketed product and optimized formulation. (Readings were taken in triplicate ( $n=3$ ) and averaged (data given as mean \pm SD)

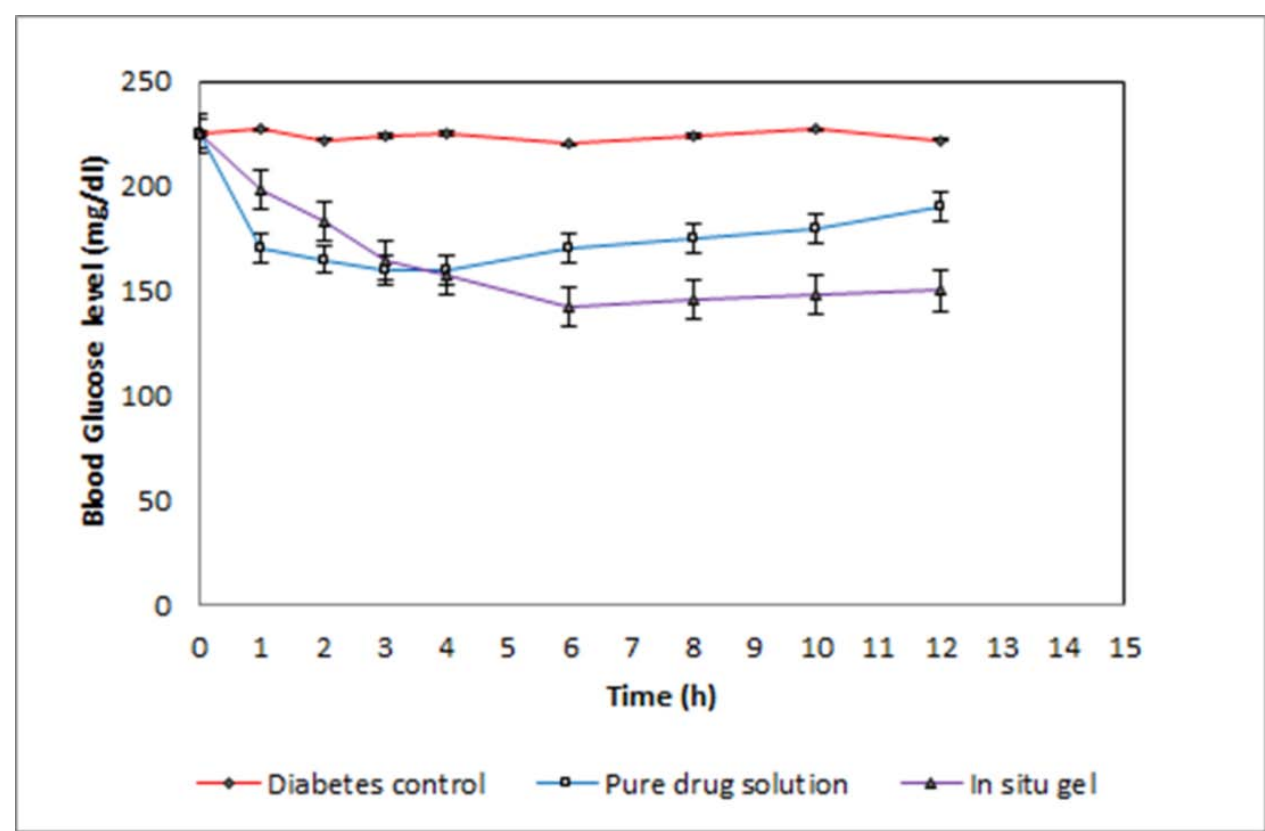

Fig. 7: In vivo pharmacodynamic study showing reduction in blood glucose level following oral administration of MH solution and the insitu gel in streptozotocin induced diabetic rabbits $(n=6$, data given as mean \pm SEM)

\section{Pharmacodynamic study}

The results of the pharmacodynamic study indicated that the optimized formulation showed a reduction in blood glucose levels in the Wistar rats (fig. 7).

Also, prolonged release of the MH in situ gel has been observed due to the persistence of drug in the body [52].

\section{Histological safety evaluation}

The light microphotographs of pancreatic tissue samples (Hematoxylin and Eosin stained, 40x) of the normal control as seen in fig. 8 showed (a) normal architecture of the islets of Langerhans and these were interspersed in between the acinar cells. The blood vessels and pancreatic tissue were also intact without any red swelling or inflammatory infiltration in the control group. However, the diabetic control group (b) showed pathological changes in both the exocrine and endocrine components. The acinar cells were swollen and small vacuoles were seen in almost all the cells. The $\beta$ cells of the islet of Langerhans were almost entirely destroyed in the STZ treated group as seen in the fig. 8b where no islets are visible. In the group treated with MH solution (c) there was slight distortion in the architecture while in the optimized formulation i.e. MH in situ gel treated group (d), the endocrine portion of pancreas indicated less severe atrophic changes in the acinar cells and the border between the endocrine and exocrine portions were more distinct. Normal architecture of exocrine glands with columnar epithelial cells with a basal nucleus and pink staining secretions was observed with no degeneration islets of Langerhans cells. In fact, the replenishment of insulin-producing pancreatic $\beta$ cells was observed due to this optimized, controlled release formulation of MH in situ gel which is crucial in treating diabetes and its complications thus overcoming inadequacies of the current treatment strategies. 

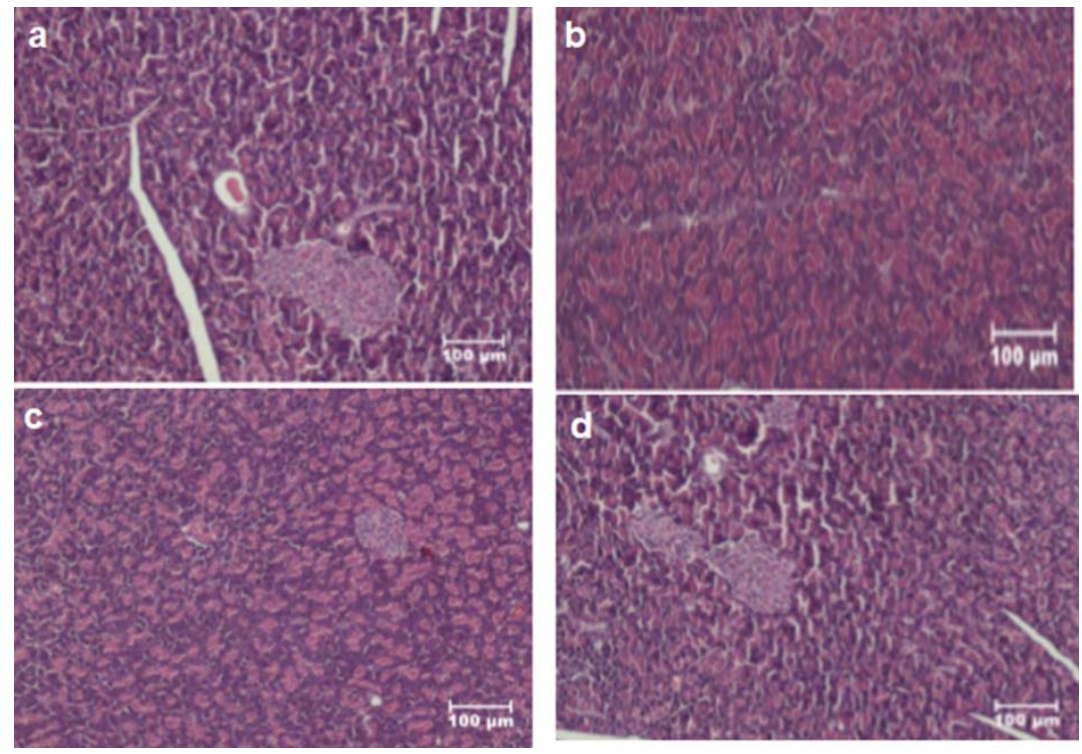

Fig. 8: Light microphotographs of (a) control mice showing normal pancreas b) diabetic mice with streptozotocin-induced diabetic pancreas showing degenerative, necrotic changes and disappearance of the $\beta$-cells $c$ ) diabetic mice treated with Metformin solution showing reappearance of the $\beta$-cells d) diabetic mice treated with optimized MH in situ gel showing marked improvement with regeneration of $\beta$ cells of the islets of Langerhans) $(* n=6$, all values expressed as mean \pm SD)

These results are in agreement with previous studies done [53] which have confirmed that there is a progressive deterioration in $\beta$-cell function and mass in Type 2 diabetes. The islet function declined to $50 \%$, at the time of diagnosis and a reduction in $\beta$-cell mass of about $60 \%$ was shown at necropsy, the latter being attributable to accelerated apoptosis. Impaired $\beta$-cell function and possibly $\beta$-cell mass appear to be reversible, particularly at early stages of the disease. Interventions to preserve or rejuvenate $\beta$-cells can thus help improve the function of these cells [54]. Thus, histopathological studies have confirmed that the administration of the optimized SR formulation of $\mathrm{MH}$ in situ gel could again increase the number and size of the islet cells.

\section{Stability studies}

Stability studies carried out on the optimized formulation as per ICH guidelines (Q1C) revealed no significant changes in the physicochemical properties, gelling capacity or drug release of the formulation even on the aging of the in-situ gel under the different storage conditions. Also, shelf life of up to $2 \mathrm{y}$ was observed.

\section{CONCLUSION}

It can be concluded that a promising, stable sustained release, liquid oral floating in situ gelling systems of Metformin Hydrochloride that met the official specifications of sustained drug release could be successfully developed using Statistical design and optimization techniques. Therapeutic concentrations of the drug could be achieved in plasma in a controlled manner and the drug release was sustained for $12 \mathrm{~h}$ when compared to the conventional dosage forms (tablets). The formulation also helped in the regeneration of the $\beta$ cells of the islets of Langerhans. Incorporation of large doses of drug would be possible with such liquid oral formulations and the simple, economic method of formulation indicate the feasibility and ease of production on a larger scale.

\section{ACKNOWLEDGMENT}

The authors express their heartfelt thanks to the Management, Director and Staff of Karnataka College of Pharmacy, Bangalore, India for providing the necessary support and facilities for this research work. This research received no specific grant from any funding agency in the public, commercial, or not-for-profit sectors.

\section{AUTHORS CONTRIBUTIONS}

All the author have contributed equally

\section{CONFLICT OF INTERESTS}

The authors declare that they have no conflicts of interest

\section{REFERENCES}

1. Xu H, Shi M, Liu Y, Jiang J, Ma TA. Novel in situ gel formulation of ranitidine for oral sustained delivery. Biomol Ther 2014;22:161-5.

2. Zhidong L, Jaiwei L, Shufang N, Hui L, Pingtian D, Weisan P. Study of an pharm alginate-HPMC based in situ gelling ophthalmic delivery system for gatifloxacin. Int J 2006;315:12-7.

3. Uchida T, Yastake T, Goto S. Utility of a mixture of the commercially available polymer as constituents of sustained release microcapsules. Chem Pharm Bull 1992;40:463-6.

4. Ravi Kumar MNV. Nano and microparticle as controlled drug delivery devices. J Pharm Sci 2000;3:234-58.

5. Rao GU, Pawan M. Buoyant sustained release drug delivery systems current potentials advancements and role of polymers: a review. Int J Clin Pharm 2012;2:1-7.

6. Rabadia N, Tiwari A, Patel G, Virani V. The floating drug delivery system and its impact on calcium channel blocker: a review article. Int J Pharm Res Dev 2011;3:107-31.

7. Sarasija S, Shyamala B. Nasal drug delivery: an overview. Indian J Pharm Sci 2005;67:19-25.

8. Jadhav SL, Banerjee SK. Formulation and evaluation of floating in situ gel of nizatidine. Int J Res Pharm Sci 2013;4:250-5.

9. Qiu Y, Park K. Environment-sensitive hydrogels for drug delivery. Adv Drug Delivery Rev 2001;53:321-39.

10. Concheiro A. Crosslinked ionic polysaccharides for stimuli sensitive drug delivery. Adv Drug Delivery Rev 2013;65:1148-71.

11. Wataru K, Yasuhiro K, Miyazaki S, Attwood D. In situ gelling pectin formulations for sustained oral delivery of paracetamol. Drug Dev Indian Pharm 2004;30:593-9.

12. Bhalerao KK, Kamble MS, Aute PP, Dange SM, Chavan RP, Vaidya KK, et al. A short review on a stomach specific floating in situ gel. J Biomed Pharm Res 2012;1:1-4.

13. Prajapati VD, Jani GK, Zala BS, Khutliwala TA. An insight into the emerging exopolysaccharide gellan gum as a novel polymer. Carbohydrate Polymers 2013;93:670-8.

14. Armin M. Stability and release kinetics of an advanced gliclazide-cholic acid formulation: the use of artificial-cell microencapsulation in slow-release targeted oral delivery of antidiabetics. J Pharm Int 2014;9:150-7.

15. Artiga AM, Acevedo FA, Martin BO. Effect of sodium alginate incorporation procedure on the physicochemical properties of nanoemulsions. Food Hydrocolloids 2017;70:191-200.

16. Narayani R, Bagavad Gita V, Amarnathan T. Preparation and evaluation of alginate films for periodontal drug delivery. Trends Bio Mater Artif Organs 2000;14:1-4. 
17. Tapan AM, Villafuerte RL. Effect of formulation and process variables on the release behavior of amoxicillin matrix tablets. Drug Dev Indian Pharm 2004;30:901-8.

18. Jaipal A, Pandey MM, Charde SY, Raut PP, Prasanth KV, Prasad RG. Effect of HPMC and mannitol on drug release and bio adhesion behavior on buccal discs of buspirone hydrochloride: in vitro and in vivo pharmacokinetic studies. Saudi Pharm J 2015;23:315-26.

19. Ching MO, Paul WSH, Lai WC. A study on the impact of hydroxypropyl methylcellulose on the viscosity of PEG melt suspensions using surface plots and principal component analysis. AAPS PharmSciTech 2015;16:466-77.

20. Miyazaki S. The effect of taste-masking agents on in situ gelling pectin formulations for sustained oral delivery of paracetamol and ambroxol. Int J Pharm 2005;297:38-49.

21. Abraham S, Naufal M, Peter V. Formulation and evaluation of gastro-retentive drug delivery system containing a combination of glipizide and metformin hydrochloride. Asian J Pharm Clin Res 2016;9:236-40.

22. Kim D, Park J. Development and pharmaceutical approach for sustained release metformin succinate tablets. J Drug Del Sci Tech 2015;30:90-9.

23. Kavin G, Joshi P, Shah M, Ramkishan A, Patel J. Formulation and evaluation of periodontal in-situ gel. Int J Pharm Investig 2013;3:29-41.

24. Chunming Su, Donald LS. In situ infrared speciation of adsorbed carbonate on aluminium and iron oxides. Clay Miner Soc 1997; 45:814-25.

25. Shashank NN, Bharani SS, Thakur RS. Formulation and evaluation of $\mathrm{pH}$ triggered in situ ophthalmic gel of moxifloxacin HCl. Int J Pharm Sci 2012;4:452-9.

26. Nagarwal RC, Srinatha A, Pandit JK. In situ forming formulation: development, evaluation, and optimization using $3^{3}$ factorial design. AAPS PharmSciTech 2009;10:977-84.

27. Kubo W, Miyazaki S, Attwood D. Oral sustained delivery of paracetamol from in situ gelling gellan and sodium alginate formulations. Int J Pharm 2003;258:55-64.

28. Nassour L, Hasan I, El-Hammadi M, Abboud H. Floating in-situgelling gellan formulations of metformin hydrochloride. J Chem Pharm Res 2014;6:1509-17.

29. Swamy NG, Abbas Z. Mucoadhesive in-situ gels as nasal drug delivery systems: an overview. Asian J Pharm Sci 2013;7:168-80.

30. Mohanambal E, Arun K. Formulation and evaluation of $\mathrm{pH}-$ triggered in-situ gelling system of levofloxacin. Int J Pharm Educ Res 2011; 45:59, 60.

31. Panwar P, Chourasiya D, Jain G, Sheorey RV. Formulation and evaluation of oral floatable in-situ gel of diltiazem hydrochloride. Int J Novel Drug Del Tech 2012;2:264-70.

32. Rajinikan PS, Balasubramaniam J, Mishra B. Development and evaluation of a novel floating in situ gelling system of amoxicillin for the eradication of helicobacter pylori. Int J Pharm 2007;335:114-22.

33. Thomas LM. Formulation and evaluation of floating oral in-situ gel of metronidazole. Int J Pharm Sci 2014;6:265-9.

34. Miyazaki S. In situ gelling xyloglucan formulations for sustained release ocular delivery of pilocarpine hydrochloride. Int J Pharm 2001;229:29-36.

35. Geethalakshmi A, Roopa K, Poornima S, Sajal KJ, Venkatesh DP. Temperature triggered in situ gelling systems for betaxolol in glaucoma. J Appl Pharm Sci 2013;3:153-9.

36. Patel DM, Patel DK, Patel CN. Formulation and evaluation of floating oral in situ gelling system of amoxicillin. Int Scholarly Res Net 2011;8:1-8.
37. Moin K. Sodium alginate-based in-situ gelling system of famotidine: preparation and in vivo characterizations. e-JST 2010;5:27-42.

38. Preetha PJ, Karthika K, Rekha NR, Elshafie K. Formulation and evaluation of in situ ophthalmic gel of diclofenac sodium. J Chem Pharm Res 2010;2:528-35.

39. Miyazaki S, Endo K, Kawasaki N, Kubo W, Watanabe H, Attwood D. Oral sustained delivery of paracetamol from in situ gelling xyloglucan formulations. Drug Dev Indian Pharm 2013;29:113-9.

40. Higuchi T. Mechanism of sustained-action medication: theoretical analysis of rate of release of solid drugs dispersed in solid matrices. J Pharm Sci 1963;52:1145-9.

41. Korsmeyer RW, Gurny R, Peppas NA. Mechanisms of solute release from porous hydrophilic polymers. Int J Pharm 1983;15:25-35.

42. Peppas NA. Analysis of fickian and non-fickian drug release from polymers. Pharm Acta Helv 1985;60:110-1.

43. Ahmed TA, Badr Eldina SM, Ahmed OAA, Aldawsari H. Intranasal optimized solid lipid nanoparticles loaded in situ gel for enhancing trans-mucosal delivery of simvastatin. J Drug Delivery Sci Technol 2018;48:499-508.

44. Swathi G, Lakshmi PK. Design and optimizations of hydrodynamically balanced oral in situ gel of glipizide. J Appl Pharm Sci 2015;5:31-8.

45. Deeds MC, Anderson JM, Armstrong AS. Single-dose streptozotocin-induced diabetes: considerations for study design in islet transplantation models. Lab Anim 2011;45:13140.

46. Stepensky D, Friedman M, Srour W, Raz I, Hoffman A. Preclinical evaluation of pharmacokinetic-pharmacodynamic rationale for oral CR metformin formulation. J Control Release 2001;71:107-15.

47. Nurdiana S. Changes in pancreatic histology, insulin secretion and oxidative status in diabetic rats following treatment with ficus deltoidea and vitexin. BMC Complement Altern Med 2017;17:290.

48. Madan JR, Adokar BR, Dua K. Development and evaluation of in situ gel of pregabalin. Int J Pharm Investig 2015;56:227-33.

49. Wamorkar V, Varma MM, Manjunath SY. Formulation and evaluation of stomach-specific in-situ gel of metoclopramide using natural, biodegradable polymer. Int J Res Pharm Biomed Sci 2011;2:193-97.

50. Sarrof R, Shaikh A, Pawar Y, Kumbhar S. Sodium alginate-based oral in situ floating gel of metformin hydrochloride. Res J Pharm Bio Chem Sci 2012;3:890-7.

51. Nalawade VV, Peepliwal AL, Shidaye SS, Mhadgut A, Pandey S. Formulation and evaluation of oral sustained release dry suspension of metformin hydrochloride. Eur J Pharm Med Res 2016;3:447-57.

52. Ghica MV, Hirjau M, Lupulease D, Pirvu CD. Flow and thixotropic parameters for rheological characterization of hydrogels. Molecules 2016;21:786.

53. Sara B. Development of an injectable slow release Metformin formulation and evaluation of its potential antitumor effects. Sci Rep 2018;8:3929.

54. Wajchenberg BL. $\beta$-cell failure in Diabetes and preservation by clinical treatment. Endocr Rev 2007;28:187-218.

55. Walvekar MV, Potphode ND, Desai SS, Deshmukh VM. Histological studies of langerhans of the pancreas in diabetic mice after curcumin administration. Int J Pharm Clin Res 2016;8:1314-8. 